- IEEE.org

- IEEE Xplo

$\underline{\text { Conferences }}>\underline{20196 \text { th International Confer... }}$

\title{
Outdoor Air Pollution in Kumbo Cameroun
}

\author{
Publisher: IEEE \\ Author(s) \\ M.E. Emetere; T.V. Omotosho; T.E. Oladimeji
}

\begin{abstract}
:
In this paper, the air quality of Kumbo-Cameroon was investigated. Aerosol optical depth (AOD) dataset for fourteen years was obtained from the Multi-angle Imaging Spectro-Radiometer (MISR). The raw dataset was processed and treated. The aerosol loading over the research location was obtained from the AOD datasets. It was observed that the main pollution is from anthropogenic emission and Sahara dust. The current aerosol loading over Kumbo is high and it is gradually reducing by $1.81 \%$, though not significantly. The data presented is essential for ground measurement over the research area.

Published in: 2019 6th International Conference on Space Science and Communication (IconSpace)

Date of Conference: 28-30 July 2019

Date Added to IEEE Xplore: 30 December 2019

ISBN Information:

ISSN Information:

INSPEC Accession Number: 19277416

DOI: $10.1109 /$ IconSpace.2019.8905924

Publisher: IEEE

Conference Location: Johor Bahru, Malaysia, Malaysia

\section{Introduction}

Outdoor air pollution is the emission of air pollutant which could be in form of combination of particulate matter, chemicals and biological materials which react with each other to form hazardous particles. Outdoor air pollution is the presence of harmful particulates or chemical substances in the atmosphere at duration and concentrations exceeding the required limits (1). An example of such chemical substances or particulates include ozone [O3], airborne lead [Pb], carbon monoxide [CO], sulphur oxides [SOx] and nitrogen oxides [NOx] $(2,8)$ which contributes to diseases such as breathing problems, chronic diseases which may lead to premature mortality. Exposure to outdoor air pollution is one of deadly problems public health and environmentalist are yet to solve (3). WHO (4) estimated that indoor and outdoor air pollution causes over three million deaths yearly.
\end{abstract}

\section{Authors}




\section{Figures}

\section{References}

\section{Keywords}

\section{Metrics}

More Like This

Bayesian Merging of MISR and MODIS Aerosol Optical Depth Products Using Error

Distributions From AERONET

IEEE Journal of Selected Topics in Applied Earth Observations and Remote Sensing

Published: 2017

$\underline{\text { Retrieval and Validation of Atmospheric Aerosol Optical Depth From AVHRR Over China }}$

IEEE Transactions on Geoscience and Remote Sensing

Published: 2016

Show More

Top Organizations with Patents on Technologies Mentioned in This Article

\section{References}

1. JH Seinfeld and S. Pandis, Atmospheric chemistry and physics: from air pollution to climate change, New York:John Wiley, vol. 2nd, pp. 34-65, 2006.

Google Scholar

2. K. Bickerstaff and G. Walker, "Public understandings of air pollution: The localisation of environmental risk", Global Environ. Change, vol. 11, pp. 133-145, 2001.

CrossRef Google Scholar

3. M.E. Emetere, "Generation Of Atmospheric Constants Over Some Locations In West Africa:

A Theoretical Aid for Measuring Instruments Design", International Journal of Engineering Research in Africa, vol. 27, pp. 119-146, 2016.

CrossRef Google Scholar

4. [online] Available: http://www.who.int/mediacentre/factsheets/fs313/en/.

5. Thaddaeus Egondi, Catherine Kyobutungi, Nawi Ng, Kanyiva Muindi, Samuel Oti, Steven van de Vijver, et al., "Community Perceptions of Air Pollution and Related Health Risks in Nairobi Slums", International Journal of Environmental Research and Public Health, vol. 10, pp. 4851-4868, 2016.

CrossRef Google Scholar 
6. M. E. Emetere, "Impacts of recirculation event on aerosol dispersion and rainfall patterns in parts of Nigeria", Global Nest Journal, vol. 19, pp. 344-352, 2017.

Google Scholar

7. Moses Eterigho Emetere, "Investigations on aerosols transport over micro- and macro- scale settings of West Africa", Environ. Eng. Res., vol. 22, pp. 75-86, 2017.

CrossRef Google Scholar

8. A Nemmar, JA Holme, I Rosas, PE Schwarze and E. Alfaro-Moreno, "Recent advances in particulate matter and nanoparticle toxicology: a review of the in vivo and in vitro studies", Biomed Res Int., vol. 2013, pp. 279371, 2013.

CrossRef Google Scholar

9. S.N. Kim, K.H. Lee and K.H. Ahn, "The effects of compact city characteristics on transportation energy consumption and air quality", Korea Plan. Assoc., vol. 44, pp. 231-246, 2009.

Show Context Google Scholar

10. Y. Liu, Z. Wang, J. Wang, R. Ferrare, R. Newsom and E. Welton, "The effect of aerosol vertical profiles on satellite-estimated surface particle sulphate concentrations", Remote Sensing of Environment, vol. 115, pp. 508-513, 2011.

CrossRef Google Scholar

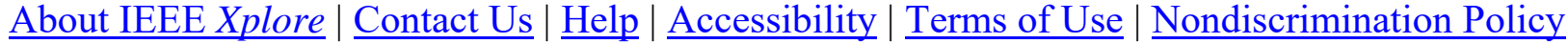
$|\underline{\text { Sitemap }}|$ Privacy \& Opting Out of Cookies

(C) Copyright 2020 IEEE - All rights reserved. Use of this web site signifies your agreement to the terms and conditions. 